\title{
PENERAPAN ELECTRONIC CUSTOMER RELATIONSHIP MANAGEMENT (E-CRM) GUNA MENINGKATKAN LOYALITAS PASIEN RUMAH SAKIT
}

\author{
${ }^{1}$ Adiiba Dwikanthi, ${ }^{2}$ Hendri Irawan \\ ${ }^{1,2}$ Program Studi Informasi, Fakultas Teknologi Informasi, \\ Universitas Budi Luhur, Jakarta Selatan, 12260 \\ *11512502525@student.budiluhur.ac.id, ${ }^{2}$ hendri.irawan@budiluhur.ac.id
}

\begin{abstract}
.
The hospital is an organization that has an important role in efforts to improve public health. In running its business, the hospital continues to strive to improve services for its patients so as not to move to competitors. Rumah Sakit Ibu dan Anak (RSIA) XYZ is one of the providers of quality medical services for mothers and children. The hospital continues to strive to improve the quality of customer relations by providing the best service for its patients. Problems that arise in the hospital are related to unsatisfactory services that make patients disappointed. One of them is a fairly long procedure, which causes the patient to wait a long time to get action. An information system prototype has been designed using the concept of Electronic Customer Relationship Management (e-CRM). This concept provides the best service for patients who have not moved to competitors. System Development Life Cycle (SDLC) method used is prototyping technique. This application prototype was built using PHP programming with the MySQL database. The features contained in the prototype include the appointment of the doctor, the witness feature, the complaint feature, the askdoctor feature, and the promo feature that is useful for getting patients and improving the quality of service to maintain patient loyalty at RSIA XYZ.
\end{abstract}

Keywords: patient loyalty, prototype e-CRM, hospital information systems

\section{PENDAHULUAN}

Rumah sakit merupakan organisasi yang terdapat pada bidang tenaga medis professional yang terorganisir. Selain itu rumah sakit juga menyediakan sarana kedokteran yang permanen untuk menyelenggarakn pelayanan, asuhan perawatan yang berkesinambungan, diagnosis, dan pengobatan pasien [1].

RSIA XYZ (bukan nama sebenarnya) sebagai objek penelitian, merupakan salah satu penyedia layanan medis berkualitas yang sudah berdiri sejak tahun 1973 berlokasi di Jakarta Pusat. Awalnya rumah sakit ini merupakan sebuah klinik kecil dan kemudian diperbesar menjadi beberapa blok yang meliputi layanan pada bidang ibu dan anak.

RSIA XYZ terus berusaha untuk mengembangkan layanan medis yang terbaik. Oleh karena itu perlu meningkatkan hubungan yang baik antara customer dengan perusahaan melalui pendekatan dengan konsep Electronic Customer Relationship Management (E-CRM). Konsep ini bertujuan untuk memberikan pelayanan terbaik untuk customer sehingga mereka tidak pindah ke kompetitor.

Electronic Customer Relationship Management merupakan suatu metode yang digunakan untuk mengelola hubungan yang baik antara perusahaan dengan customer. Metode ini digunakan dalam rangka peningkatan loyalitas penggunaan produk atau jasa yang ditawarkan oleh perusahaan melalui pemanfaatan media elektronik. Dengan adanya e-CRM ini pihak perusahaan dapat mengintegrasikan dan mengotomati-sasi proses layanan pelanggan dalam bidang penjualan, pemasaran, dan layanan 
produk atau jasa yang berkaitan dengan perusahaan [2], serta dapat memberikan pelayanan yang lebih baik sebagai kelanjutan meningkatkan hubungan yang lebih personal dengan pelanggan [3].

Berdasarkan hasil wawancara peneliti menyimpulkan beberapa masalah yang terdapat di RSIA XYZ, yang pertama yaitu fitur appointment terhadap dokter tidak dapat diakses melalui website rumah sakit. Hal ini disebabkan karena kurangnya koordinasi antara satu unit dengan unit yang lainnya pada saat perancangan sistem. Dengan adanya masalah ini, pasien yang ingin melakukan appointment secara online merasa kecewa karena fitur tersebut tidak dapat diakses. Kedua, Tidak ada wadah pada website rumah sakit yang digunakan untuk menyampaikan testimony mengenai pelayanan di rumah sakit. Testimony ini ditujukan untuk pasien baru sehingga calon pasien merasa yakin untuk melakukan treatment di rumah sakit. Ketiga, Pasien yang kecewa terhadap pelayanan sering kali menyampaikan keluhan fatal melalui media sosial. Hal ini terjadi karena pihak rumah sakit kurang baik dalam memberikan pelayanan. Dengan adanya masalah ini, citra rumah sakit menjadi buruk. Belum adanya wadah untuk menampung testimoni dan keluhan, perusahaan sulit untuk mengetahui tingkat kepuasan pelanggan [4].

Keempat, Pasien perlu menunggu hingga beberapa waktu untuk mendapat tindakan seperti pada saat medical check-up sampai proses pembayaran. Hal ini terjadi karena proses bisnis di rumah sakit terbilang panjang. Tak jarang pasien merasa kecewa dengan pelayanan rumah sakit.

Tujuan dari penelitian ini yaitu untuk memberikan pelayanan terbaik untuk pasien pada RSIA $\mathrm{XYZ}$ sehingga mereka tidak pindah ke kompetitor atau rumah sakit yang memiliki segmentasi yang sama.

Pada saat melakukan penelitian, peneliti melakukan analisa terkait studi literatur untuk mencari teori mengenai Electronic Customer Relationship Management. Berikut ini merupakan studi literatur yang peneliti gunakan sebagai acuan dalam melakukan penelitian, yaitu : penelitian yang dilakukan oleh Agustina Sulkanawatul, Hendra Pradibta, dan Indra Dharma Wijaya dengan judul Aplikasi Customer Relationship Management (CRM) Pada Balai Kesehatan Masyarakat (BKM) Muslimat Kepanjen membahas masalah tentang BKM Muslimat melakukan sistem pendataan pasien masih dilakukan secara manual (tercatat). Penelitian ini mengunakan metode algoritma K-Means. Solusi yang didapat dari permasalahan ini yaitu membuat aplikasi Customer Relationship Management (CRM) yang secara fungsional aplikasi ini dapat mengeluarkan hasil sesuai dengan apa yang diharapkan [5].

Selanjutnya penelitian dengan judul Electronic Customer Relationship Management (E-CRM) pada RSU Assalam Gemolong membahas masalah tentang keterbatasan media promosi dalam kegiatan pemasaran informasi kesehatan. Penelitian ini menggunakan metode waterfall. Solusi yang didapat dari permasalahan ini yaitu Merancang dan membangun Electronic Customer Relationship Management (E-CRM). Penelitian ini ditulis oleh Kunto Sytariyani, Hamidjoyo, dan Sara Adelya [6].

Penelitian dengan judul Pemodelan Electronic Customer Relationship Management (E-CRM) pada Rumah Sakit membahas masalah tentang pesatnya persaingan bisnis rumah sakit. Penelitian ini menggunakan metode Zachman Framework. Solusi yang didapat dari permasalahan ini yaitu model reservasi online customer service online, dan layanan pelanggan berbasis SMS. Penelitian ini ditulis oleh Vidila Rosalina dan Thoha Nurhadiyan [7].

\section{METODOLOGI PENELITIAN}

Dalam melakukan penelitian, peneliti melakukan beberapa tahapan untuk analisa dan perancangan yang dilakukan di RSIA XYZ. Metode pengembangan sistem menggunakan prototyping technique. Tahapan penelitian dapat dilihat pada Gambar 1. 


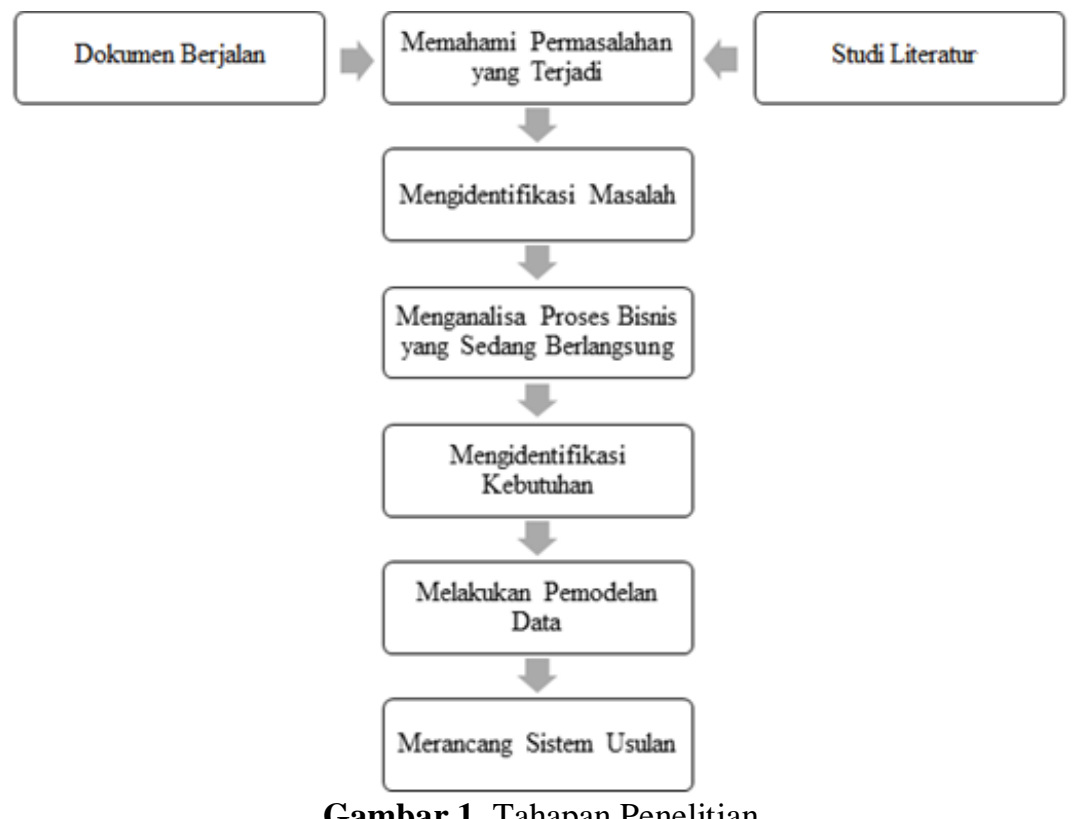

Gambar 1. Tahapan Penelitian

Berdasarkan Gambar 1, tahapan penelitian ini dapat diuraikan sebagai berikut:

a. Memahami Permasalahan yang Terjadi

Dalam memahami permasalahan yang terjadi, peneliti menggunakan teknik wawancara kepada pihak yang relevan mulai, serta observasi melakukan pengamatan langsung ke objek penelitian. Peneliti juga mempelajari dokumen berjalan untuk mengetahui kebutuhan data. Studi literatur dilakukan untuk mendapatkan teori serta tulisan baik jurnal maupun prosiding terkait penelitian yang dilakukan sebelumnya.

b. Mengidentifikasi Masalah

Tahapan ini merupakan tahapan yang dilakukan untuk mengetahui sebab dan akibat terjadinya masalah di perusahaan.

c. Menganalisa Proses Bisnis yang Sedang Berlangsung

Tahapan ini merupakan tahapan yang dilakukan guna mengetahui proses bisnis yang terdapat pada perusahaan.

d. Mengidentifikasi Kebutuhan

Tahapan ini merupakan tahapan untuk mengetahui kebutuhan yang diperlukan untuk perancangan sistem

e. Melakukan Pemodelan Data

Tahapan ini dilakukan untuk mendukung proses analisa data

f. Merancang Sistem Usulan

Tahapan ini merupakan tahapan perancangan sistem dengan membuat prototype Electronic Customer Relationship Management (E-CRM).

\section{HASIL DAN PEMBAHASAN}

RSIA XYZ yang berdiri sejak 1973 berlokasi di Jakarta Pusat selalu berusaha memberikan pelayanan terbaik untuk para pasiennya. Berdasarkan permasalahan yang sudah diidentifikasi melalui hasil wawancara, observasi dan dokumentasi, berikut ini merupakan hasil dan pembahasan yang sudah peneliti lakukan. Sebagai awalan yaitu memetakan tahapan CRM beserta aspek CRM ke dalam bentuk tabel matrik. Tahapan CRM yaitu Acquire, Enhance dan Retain. Sedangkan aspek CRM yaitu people, process dan technology. Selanjutkan dilakukan pemetaan analisa terkait as is system (sistem berjalan) dan to be system (sistem usulan). Hasil analisa as is system dan to be system dapat dilihat pada Tabel 1. 
Tabel 1. Analisa As Is System dan To Be System

\begin{tabular}{|c|c|c|}
\hline & Acquire & Iendapatkan) \\
\hline & As Is System & To Be System \\
\hline & $\begin{array}{c}\text { a.Memasang } \\
\text { promo di } \\
\text { website }\end{array}$ & $\begin{array}{l}\text { a.Tetap memasang } \\
\text { promo pada website } \\
\text { b. } \\
\text { promo ke e-mail } \\
\text { pasien }\end{array}$ \\
\hline & Enhance & Meningkatkan) \\
\hline & As Is System & To Be System \\
\hline & $\begin{array}{c}\text { a. Mengirimkan } \\
\text { greeting pada } \\
\text { pasien pada } \\
\text { saat pasien } \\
\text { berulang } \\
\text { tahun }\end{array}$ & $\begin{array}{cc}\text { a. } & \text { Membuat fitur } \\
& \text { appointment } \\
\text { b. } & \text { Membuat } \\
& \text { reminder } \\
\text { check-up } & \text { pasien } \\
& \text { AskDoctor } \\
\text { c. Membuat fitur } & \\
& \text { As }\end{array}$ \\
\hline & Retain (N & mpertahankan) \\
\hline & As Is System & To Be System \\
\hline & $\begin{array}{l}\text { a. } \\
\text { Menerima } \\
\text { kritik dan } \\
\text { saran pasien } \\
\text { via media } \\
\text { sosial } \\
\end{array}$ & $\begin{array}{c}\text { a. } \\
\text { Membuat fitur } \\
\text { complaint } \\
\text { b. Membuat fitur } \\
\text { testimony }\end{array}$ \\
\hline & Acquire & endapatkan) \\
\hline & As Is System & To Be System \\
\hline & $\begin{array}{l}\text { a. Staf } \\
\text { marketing } \\
\text { berkoordinasi } \\
\text { dengan unit } \\
\text { kerja lain } \\
\text { untuk } \\
\text { pengadaan } \\
\text { dan } \\
\text { memasang } \\
\text { promo }\end{array}$ & $\begin{array}{cc}\text { a. } & \text { Staf marketing } \\
\text { berkoordinasi } \\
\text { dengan unit kerja } \\
\text { lain perihal promo } \\
\text { dan memasang } \\
\text { promo } \\
\text { b. Staf marketing } \\
\text { mengirimkan } \\
\text { promo ke email } \\
\text { pasien }\end{array}$ \\
\hline & Enhance & [eningkatkan) \\
\hline & As Is System & To Be System \\
\hline d" & $\begin{array}{l}\text { a. Staf } \\
\text { marketing } \\
\text { berkoordinasi } \\
\text { dengan } \\
\text { bagian IT } \\
\text { untuk } \\
\text { mengirimkan } \\
\text { greeting pada } \\
\text { saat pasien } \\
\text { ulang tahun. }\end{array}$ & $\begin{array}{c}\text { a. Staf pendaftaran } \\
\text { informasi } \\
\text { berkoordinasi } \\
\text { dengan staf IT } \\
\text { untuk membuat } \\
\text { appointment } \\
\text { b. Sistem akan } \\
\text { mengirimkan } \\
\text { reminder } \\
\text { berdasarkan } \\
\text { appointment } \\
\text { Pasien memilih } \\
\text { dokter untuk } \\
\text { berkonsultasi }\end{array}$ \\
\hline & Retain ( & pertahankan) \\
\hline & As Is System & To Be System \\
\hline
\end{tabular}




\begin{tabular}{|c|c|c|}
\hline & $\begin{array}{c}\text { a. Staf Client } \\
\text { service } \\
\text { memilah } \\
\text { kritik dan } \\
\text { saran. } \\
\text { Kemudian } \\
\text { menghubungi } \\
\text { customer } \\
\text { sesuai } \\
\text { dengan jenis } \\
\text { media sosial. }\end{array}$ & $\begin{array}{c}\text { a. Staf Client service } \\
\text { harus standby } \\
\text { untuk mengeecek } \\
\text { notifikasi } \\
\text { complaint } \\
\text { sehingga dapat } \\
\text { langsung } \\
\text { menjawab } \\
\text { complaint tersebut. } \\
\text { Client service } \\
\text { harus standby } \\
\text { untuk mengecek } \\
\text { notifikasi } \\
\text { testimony dan } \\
\text { approve }\end{array}$ \\
\hline \multirow{9}{*}{$\frac{\sqrt{2}}{\sqrt[2]{2}}$} & \multicolumn{2}{|c|}{ Acquiring (Mendapatkan) } \\
\hline & As Is System & To Be System \\
\hline & $\begin{array}{l}\text { a. Staf } \\
\text { marketing } \\
\text { dan bagian } \\
\text { IT }\end{array}$ & $\begin{array}{c}\text { a. Staf marketing dan } \\
\text { bagian IT }\end{array}$ \\
\hline & \multicolumn{2}{|c|}{ Enhance (Meningkatkan) } \\
\hline & As Is System & To Be System \\
\hline & $\begin{array}{l}\text { a. Staf } \\
\text { markting } \\
\text { dan } \\
\text { bagian } \\
\text { IT }\end{array}$ & $\begin{array}{l}\text { a. Staf pendaftaran } \\
\text { b. Staf pendaftaran } \\
\text { c. Pasien dan dokter }\end{array}$ \\
\hline & \multicolumn{2}{|c|}{ Retain (Mempertahankan) } \\
\hline & As Is System & To Be System \\
\hline & $\begin{array}{cc}\text { a. } & \text { Staf Client } \\
\text { service }\end{array}$ & $\begin{array}{l}\text { Staf Client service } \\
\text { b. Staf Marketing }\end{array}$ \\
\hline \multirow{9}{*}{ 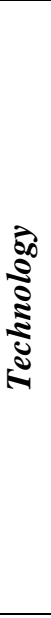 } & \multicolumn{2}{|c|}{ Acquire (Mendapatkan) } \\
\hline & As Is System & To Be System \\
\hline & \begin{tabular}{|c} 
a. $\begin{array}{c}\text { Komputer, } \\
\text { internet, dan } \\
\text { website. }\end{array}$ \\
\end{tabular} & $\begin{array}{c}\text { a. Fitur promo pada } \\
\text { website. } \\
\text { b. Fitur send promo }\end{array}$ \\
\hline & \multicolumn{2}{|c|}{ Enhance (Meningkatkan) } \\
\hline & As Is System & To Be System \\
\hline & a. Handphone & $\begin{array}{l}\text { Fitur appointment } \\
\text { Reminder Appointment } \\
\text { by WhatsApp } \\
\text { c. Fitur AskDoctor }\end{array}$ \\
\hline & \multicolumn{2}{|c|}{ Retain (Mempertahankan) } \\
\hline & As Is System & To Be System \\
\hline & a. $\quad$ Media sosial & $\begin{array}{ll}\text { a. } & \text { Fitur complaint } \\
\text { b. } & \text { Fitur testimony }\end{array}$ \\
\hline
\end{tabular}

\section{Fishbone Diagram}

Fishbone diagram merupakan suatu alat yang bersifat visual yang digunakan untuk mengidentifikasi secara detail semua penyebab yang berhubungan dengan sebuah masalah. Bentuk dari diagram ini menyerupai tulang ikan yang bagiannya meliputi kepala dan duri. Bagian kepala diibaratkan sebagai masalah yang sedang terjadi, sementara duri diibaratkan sebagai penyebab terjadinya masalah [8]. Berdasarkan wawancara dengan pihak terkait, mengerucut 2 kategori utama 
yang menyebabkan terjadinya penurunan loyalitas customer, yaitu dari sisi process dan people. Lebih lanjut, fishbone diagram analisa sebab akibat masalah pada penelitian ini dapat dilihat pada Gambar 2.

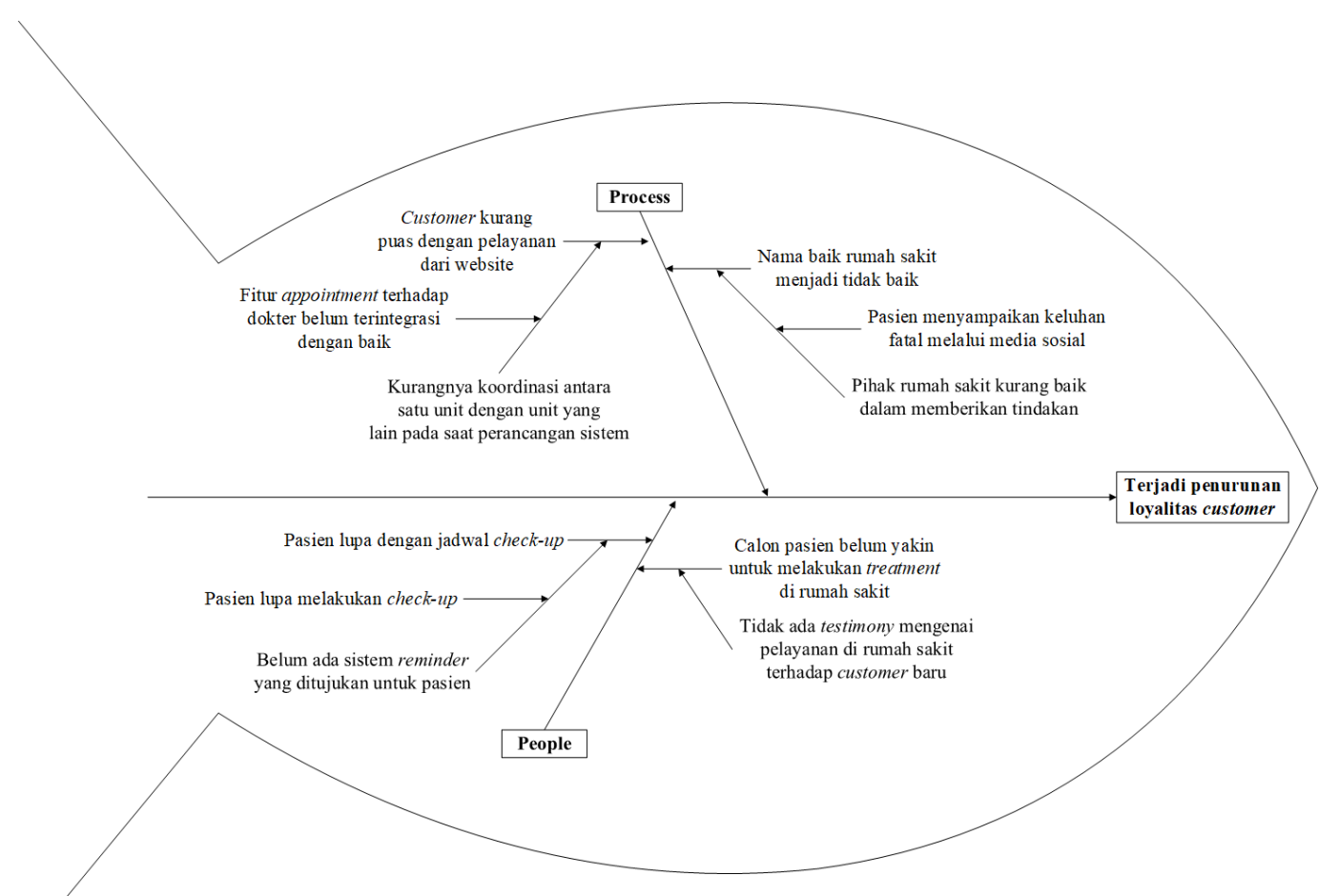

Gambar 2. Fishbone Diagram

\section{Use Case Diagram}

Diagram ini bersifat statis serta memperhatikan himpunan use case serta actor. Diagram ini sangat penting untuk mengorganisasi serta memodelkan perilaku dari sebuah sistem yang akan dibutuhkan serta diharapkan oleh pengguna [9].

a. Package Appointment

Use case diagram package appointment terdiri dari use case pilih jadwal dokter, use case view appointment, serta use case send reminder appointment by WhatsApp. Use Case Diagram Package Appointment dapat dilihat pada Gambar 3

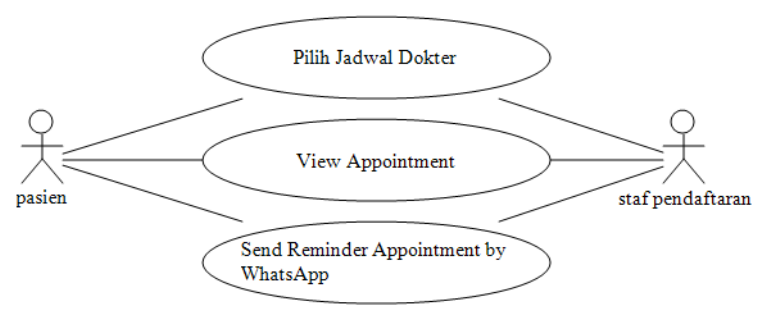

Gambar 3. Use Case Diagram Package Appointment

\section{b. Use Case Diagram Package Promo}

Use case diagram package promo terdiri dari use case entry promo dan use case view promo. Use Case Diagram Package Promo dapat dilihat pada Gambar 4. 


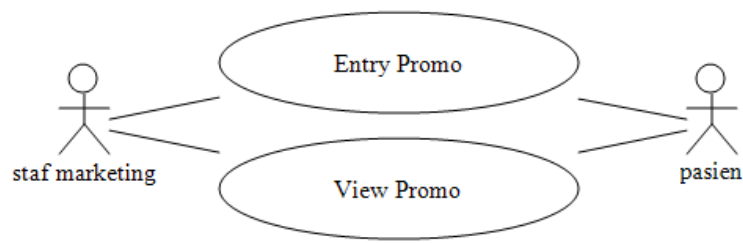

Gambar 4. Use Case Diagram Package Promo

\section{c. Use Case Diagram Package Complaint}

Use case diagram package complaint terdiri dari use case entry complaint, use case view complaint pasien, entry view complaint client service, serta entry use case tanggapi complaint. Use Case Diagram Package Complaint dapat dilihat pada Gambar 5.

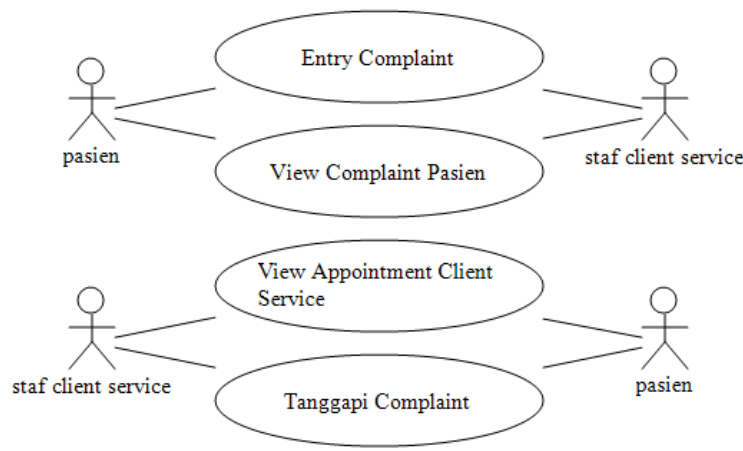

Gambar 5. Use Case Diagram Package Complaint

d. Use Case Diagram Package Testimony

Use case diagram package testimony terdiri dari use case entry testimony, use case view testimony pasien, dan use case approve testimony. Use Case Diagram Package Testimony dapat dilihat pada Gambar 6.

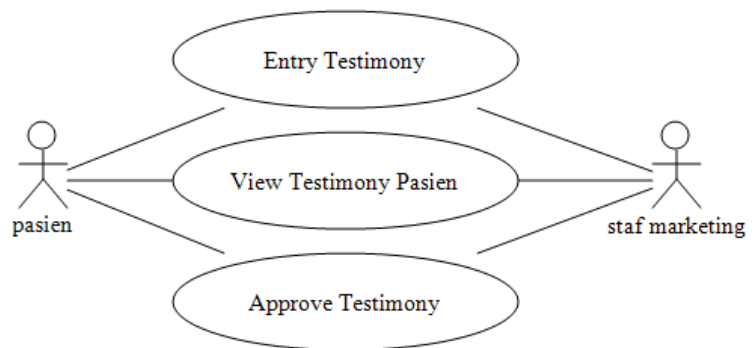

Gambar 6. Use Case Diagram Package Testimony

e. Use Case Diagram Package AskDoctor

Use case diagram package AskDoctor terdiri dari use case pilih dokter dan use case live chat. Use Case Diagram Package AskDoctor dapat dilihat pada Gambar 7.

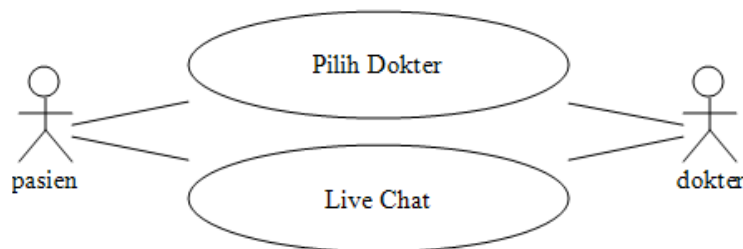

Gambar 7. Use Case Diagram Package AskDoctor 


\section{Activity Diagram}

Activity Diagram merupakan diagram yang bersifat dinamis. Activity Diagram adalah tipe khusus dari Use Case Diagram yang memperlihatkan aliran dari satu aktivitas ke aktivitas yang lain dari suatu sistem.

a. Proses Appointment

Pasien perlu mengakses halaman web kemudian melakukan login. Setelah itu pasien mengisi form appointment. Jika sudah, pasien klik button simpan maka system akan menyimpan data appointment pada database dan mengirimkan reminder kepada customer by WhatsApp. Activity Diagram Proses Appointment dapat dilihat pada Gambar 8.

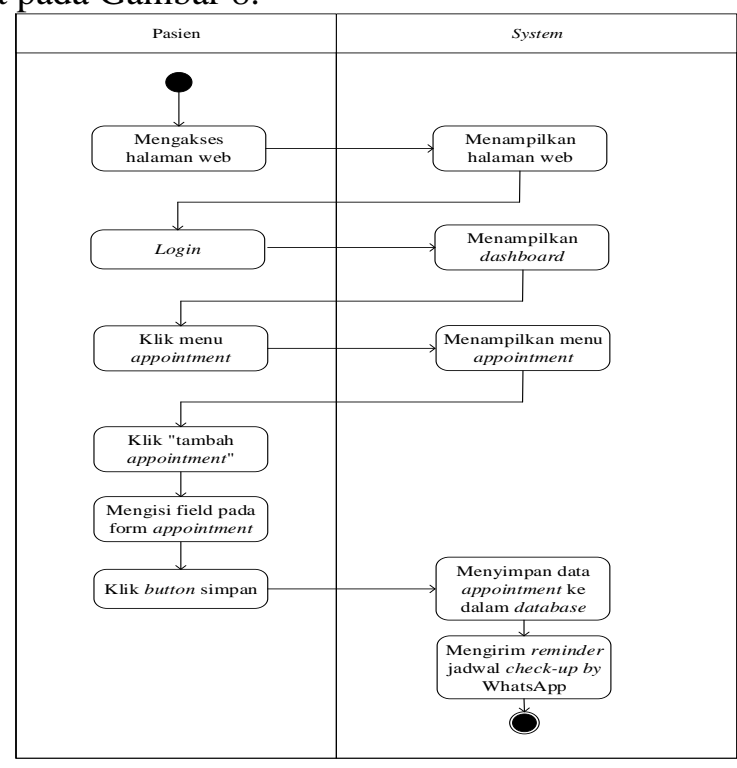

Gambar 8. Activity Diagram Proses Appointment

b. Proses Promo

Staf marketing perlu mengakses halaman web kemudian login. Kemudian staf marketing mengklik menu promo dan meng-entry form promo. Setelah form sudah terisi, staf marketing mengklik button simpan dan system akan menyimpan data promo kedalam database dan mengirimkan promo ke email pasien. Activity Diagram Proses Promo dapat dilihat pada Gambar 9. 


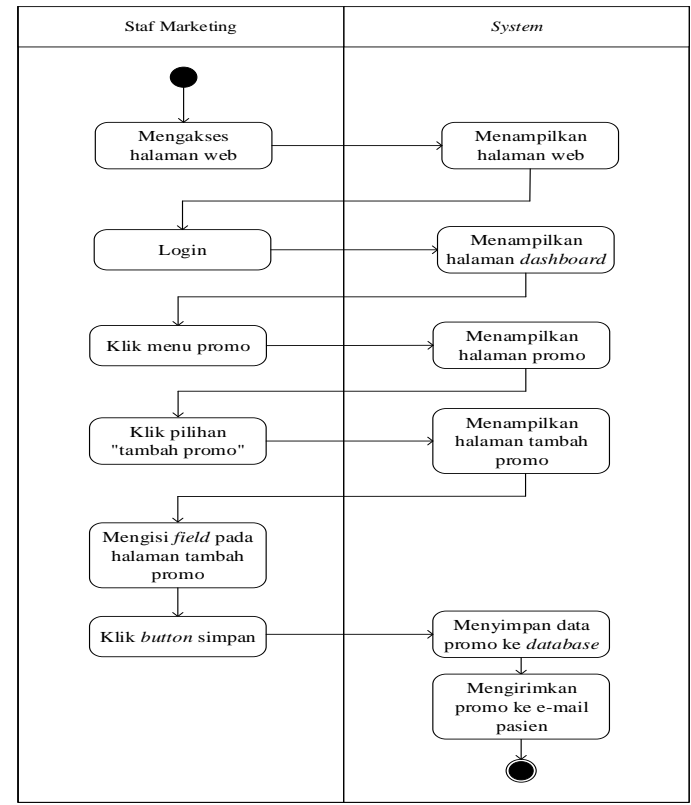

Gambar 9. Activity Diagram Proses Promo

\section{c. Proses Complaint}

Pasien perlu mengakses halaman web kemudian login. Setelah login, customer memilih menu complaint. Lalu pasien mengisi form complaint. Jika form complaint sudah terisi, pasien mengklik button simpan. Kemudian system akan menyimpan data complaint ke database. Activity Diagram Proses Complaint dapat dilihat pada Gambar 10.

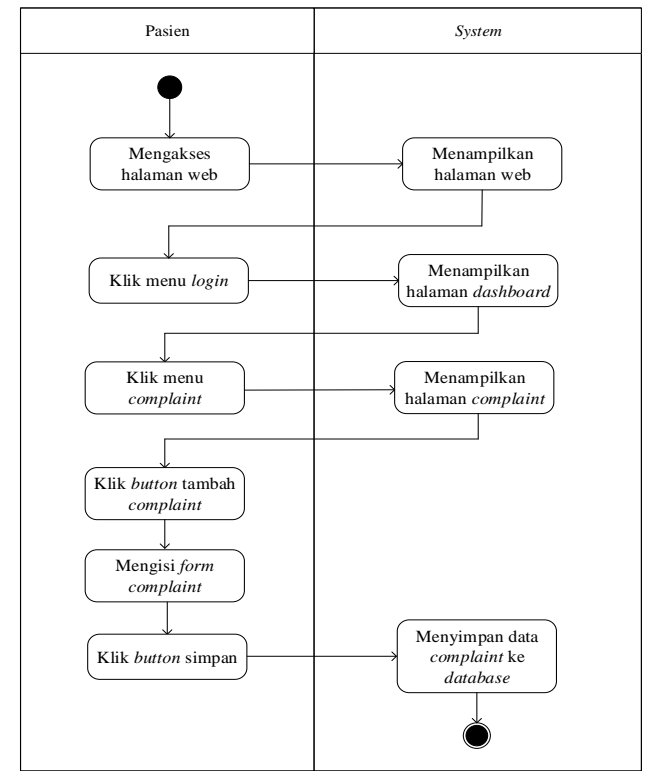

Gambar 10. Activity Diagram Proses Complaint

\section{d. Proses Testimony}

Pasien perlu mengakses halaman web kemudian login. Setelah login, pasien memilih menu testimony dan mengisi form testimony. Jika form testimony sudah terisi, pasien mengklik button simpan. Kemudian system akan menyimpan data testimony ke database. Activity Diagram Proses Testimony dapat dilihat pada Gambar 11. 


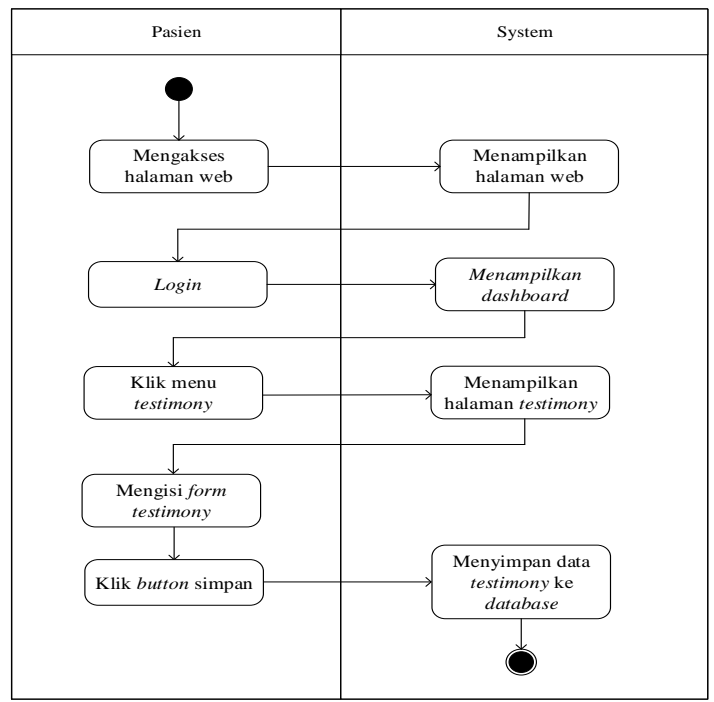

Gambar 11. Activity Diagram Proses Testimony

e. Proses AskDoctor

Pasien perlu mengakses halaman web kemudian login. Setelah login, Pasien mengklik menu AskDoctor dan memilih dokter untuk konsultasi. Activity Diagram Proses AskDoctor dapat dilihat pada Gambar 12.

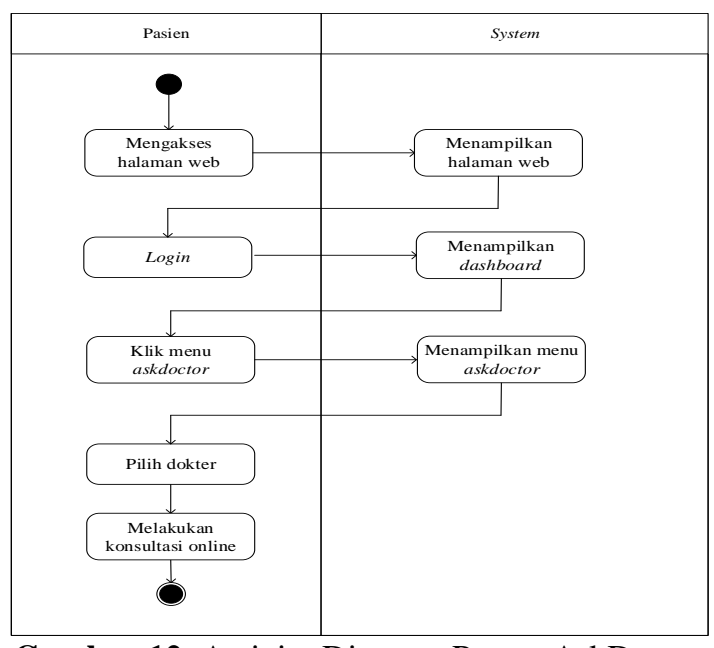

Gambar 12. Activity Diagram Proses AskDoctor

\section{Entity Relationship Diagram (ERD)}

Entity Relationship Diagram merupakan salah satu tools yang digunakan untuk memodelkan konseptual (abstraksi) data. ERD adalah tools yang digunakan untuk memodelkan struktur data dengan menggambarkan entitas dan hubungan antara entitas (relationship) [10]. ERD dalam prototype E-CRM ini dapat dilihat pada Gambar 13. 


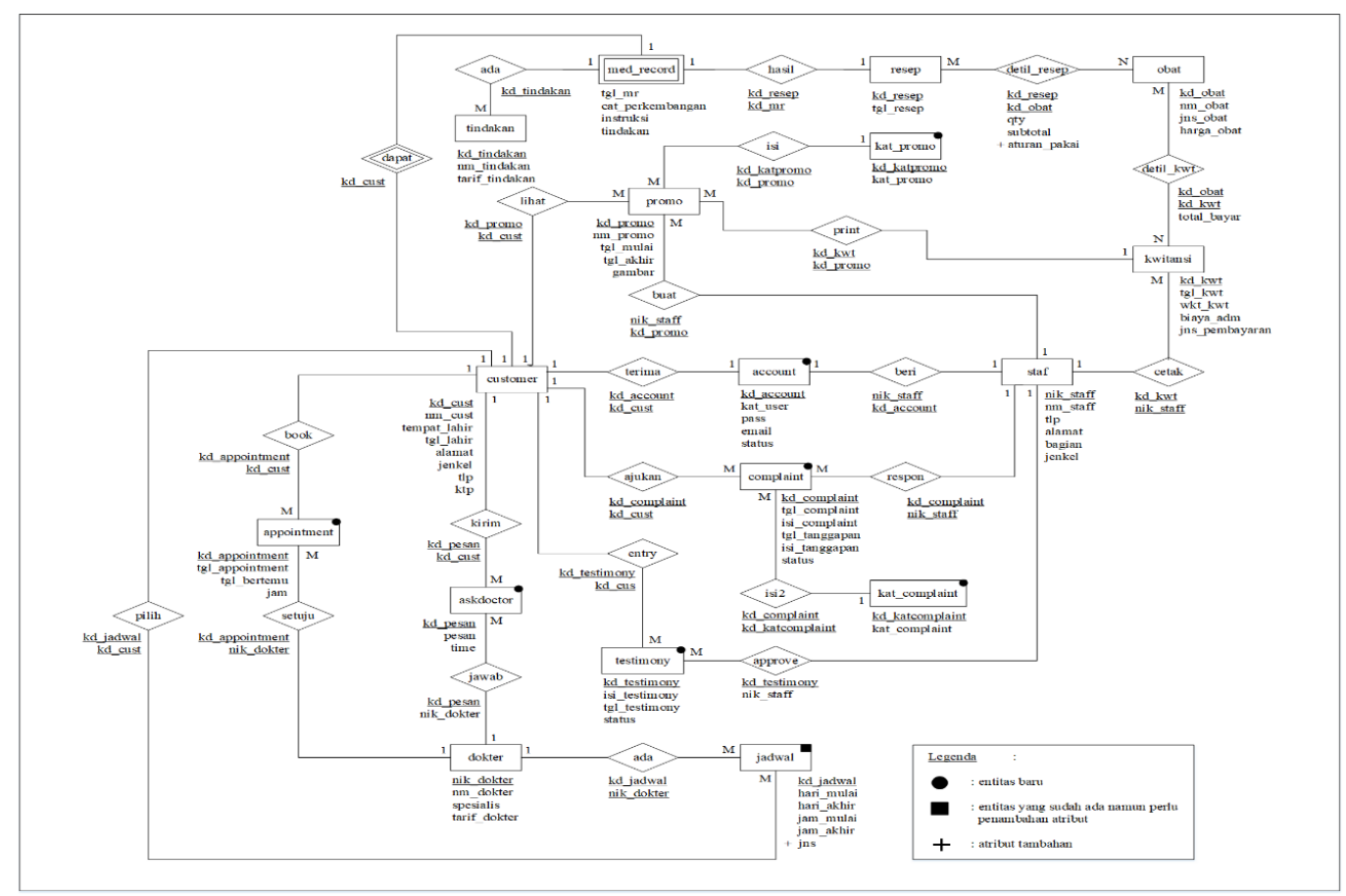

Gambar 13. Entity Relationship Diagram

ERD pada Gambar 13 merupakan model data to be system untuk prototype e-CRM. Dalam perancangan ERD to be system, peneliti menambahkan entitas testimony, kat_testimony, complaint, kat_complaint, askdoctor, dan appointment.

\section{Struktur Tampilan Menu}

Rancangan menu pada sistem usulan web RSIA XYZ dengan konsep Electronic Customer Relationship Management dapat dilihat pada Gambar 14.

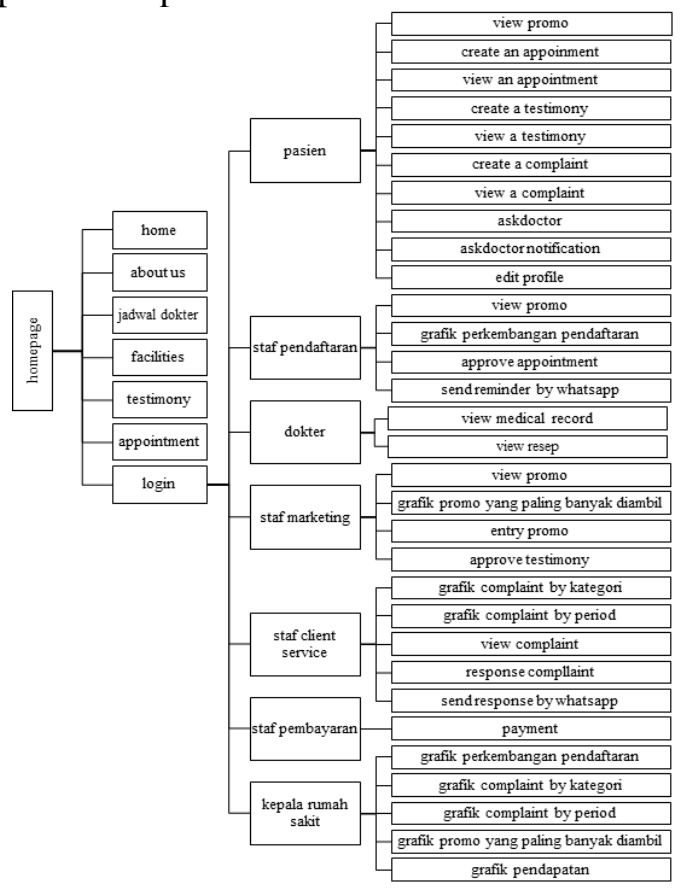

Gambar 14. Struktur Menu 


\section{Rancangan Layar}

Berikut ini meupakan rancangan layar yang terdapat pada penelitian e-CRM di RSA XYZ, yaitu:

a. Rancangan Layar Dashboard Pendaftaran

Pada rancangan layar ini menunjukan perkembangan pendaftaran pasien pada RSIA XYZ dalam periode waktu tertentu. Rancangan layar dashboard pendaftaran dapat dilihat pada Gambar 15.

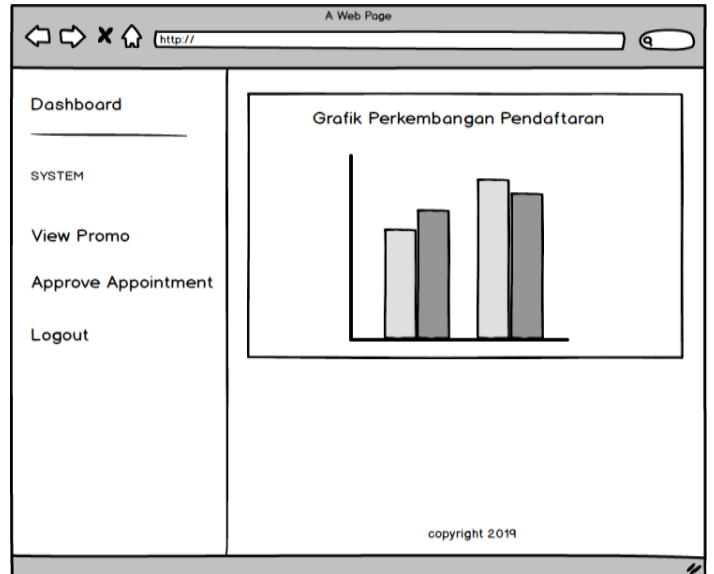

Gambar 15. Rancangan Layar Dashboard Pendaftaran

\section{b. Proses Appointment}

Pada rancangan layar view appointment terdapat tabel yang berisi tanggal appointment, tanggal bertemu, jam bertemu, dan action. Terdapat button tambah appointment yang dapat digunakan jika pasien ingin membuat appointment terhadap dokter. Rancangan layar proses appointment dapat dilihat pada Gambar 16.

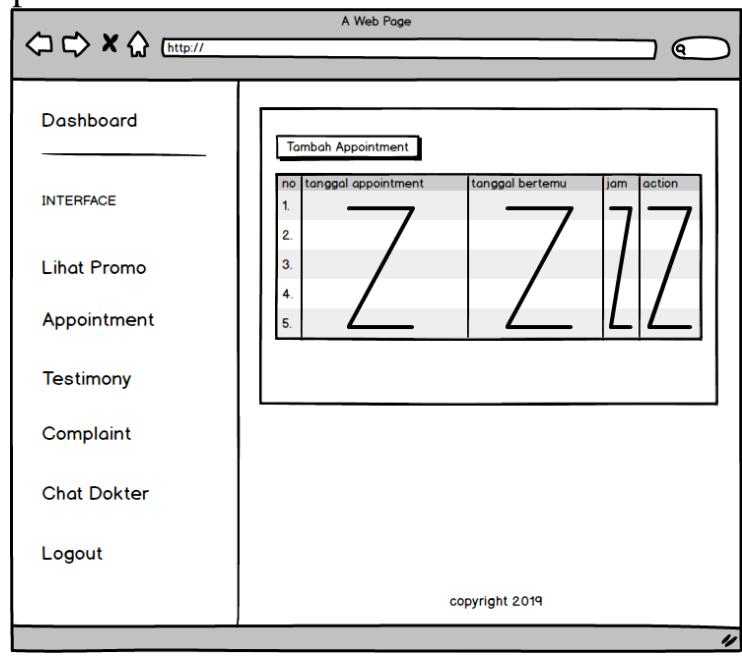

Gambar 16. Rancangan Layar Proses Appointment

\section{c. Rancangan Layar Reminder Appointment by WhatsApp}

Pada rancangan layar send reminder appointment by whatsapp terdapat informasi mengenai jadwal appointment yang sudah pernah dibuat oleh pasien. Rancangan layar reminder appointment by whatsapp dapat dilihat pada Gambar 17. 


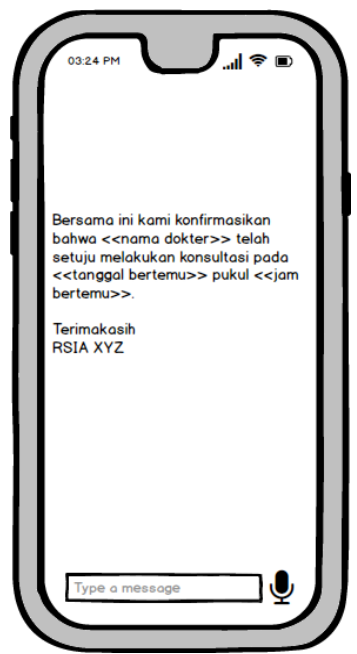

Gambar 17. Rancangan Layar Reminder Appointment by WhatsApp

\section{d. Rancangan Layar Proses Promo}

Pada rancangan layar entry promo terdapat textbox yang berisi kode promo, nama promo, tanggal mulai, tanggal akhir, serta terdapat button choose file yang digunakan untuk memilih file gambar promo. Selain itu terdapat button selesai yang digunakan jika staf marketing sudah selesai melakukan entry promo. Rancangan layar proses promo dapat dilihat pada Gambar 18.

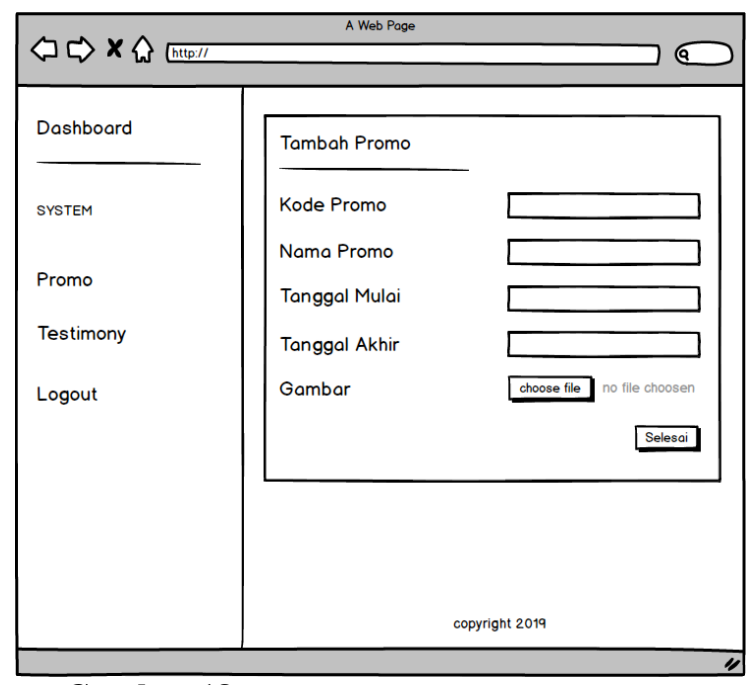

Gambar 18. Rancangan Layar Proses Promo

\section{e. Rancangan Layar Proses Complaint}

Pada rancangan layar entry complaint terdapat textbox yang berisi tanggal complaint, combobox yang berisi kategori complaint, textbox yang berisi isi complaint, dan button selesai yang digunakan jika pasien sudah selesai meng-entry complaint. Rancangan layar proses complaint dapat dilihat pada Gambar 19. 


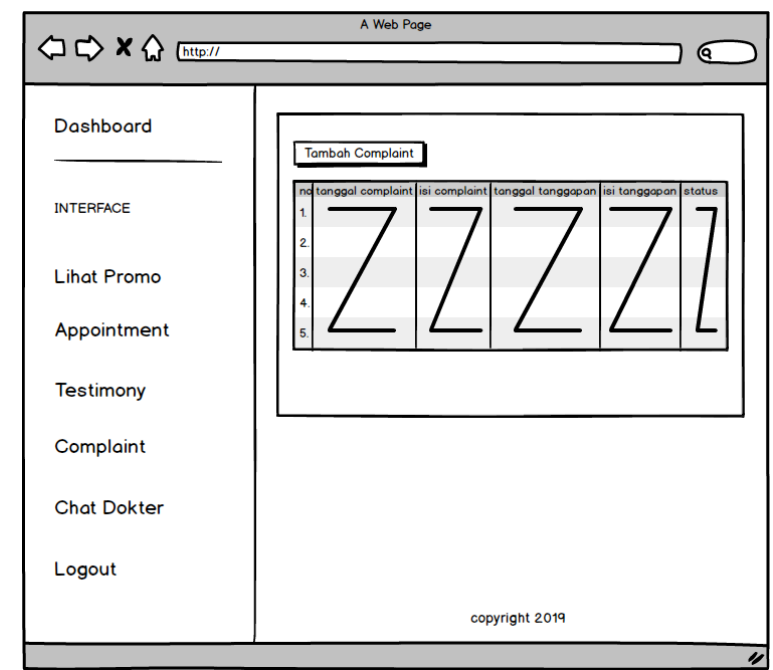

Gambar 19. Rancangan Layar Proses Complaint

\section{f. Rancangan Layar Proses Testimony}

Pada rancangan layar entry testimony terdapat textbox yang berisi isi testimony dan combobox yang berisi tanggal testimony. Selain itu juga terdapat button selesai yang digunakan jika pasien sudah selesai melakukan entry testimony. Rancangan layar proses testimony dapat dilihat pada Gambar 20.

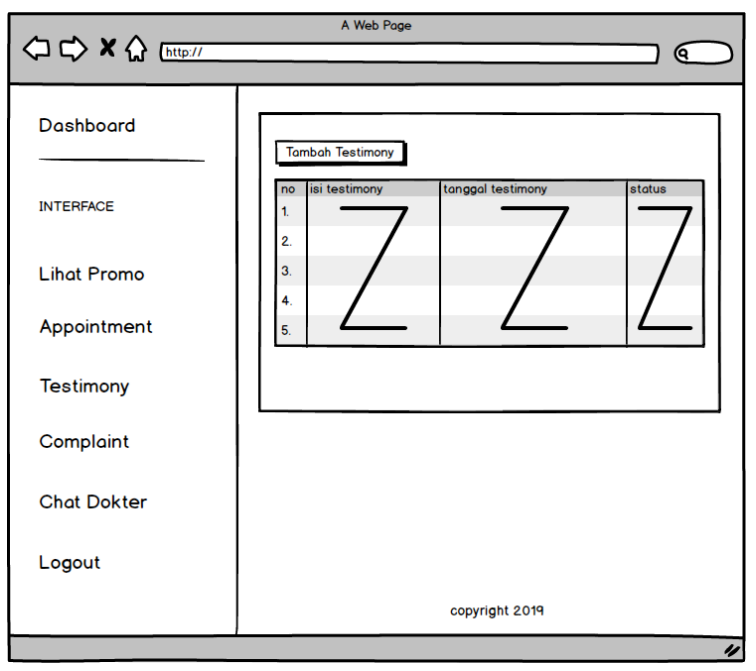

Gambar 20. Rancangan Layar Proses Testimony

g. Rancangan Layar Proses AskDoctor

Pada rancangan layar proses AskDoctor, terdapat roomchat yang digunakan pada saat pasien ingin melakukan konsultasi online terhadap dokter. Rancangan layar proses askdoctor dapat dilihat pada Gambar 21. 


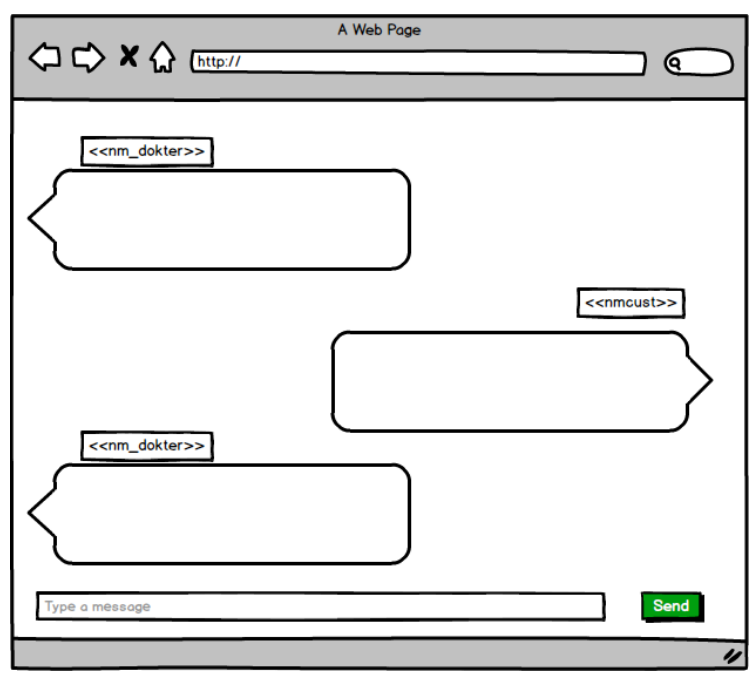

Gambar 21. Rancangan Layar Proses AskDoctor

\section{Pengujian Sistem}

Pengembangan sistem informasi dengan menggunakan metode prototipe merupakan pengembangan yang relatif cepat serta pengujian terhadap model dari aplikasi melalui proses yang iteratif. Dari desain prototipe aplikasi CRM pada RSIA XYZ peneliti melakukan pengujian sistem menggunakan black box testing. Pengujian dilakukan oleh dua orang user yaitu staf marketing dan staf client service. Pengujian dilakukan dua kali dalam waktu yang berbeda. Cuplikan beberapa hasil pengujian dapat dihat pada Tabel 2. Dari 29 fitur yang dilakukan uji coba, terdapat 3 fitur yang masih belum sesuai atau ditolak pada pengujian pertama yaitu tanggapi complaint, entri testimony dan view promo. Sudah dilakukan perbaikan dari ketiga fitur itu, serta diterima pada pengujian yang kedua. Sehingga saat ini 29 fitur / 100\% sudah diterima oleh user.

Tabel 2. Pengujian Prototipe Aplikasi CRM RSIA XYZ

\begin{tabular}{|c|c|c|c|}
\hline $\begin{array}{c}\text { Aktivitas } \\
\text { Pengujian }\end{array}$ & $\begin{array}{l}\text { Realisasi } \\
\text { yang } \\
\text { diharapkan }\end{array}$ & $\begin{array}{c}\text { Hasil } \\
\text { Pengujian }\end{array}$ & Kesimpulan \\
\hline $\begin{array}{c}\text { Masuk } \\
\text { halaman } \\
\text { awal/ } \\
\text { login }\end{array}$ & $\begin{array}{c}\text { Sistem akan } \\
\text { menampilka } \\
\text { n halaman } \\
\text { login yang } \\
\text { terdapat text } \\
\text { box berisi } \\
\text { username } \\
\text { dan } \\
\text { password. } \\
\text { Selain itu } \\
\text { terdapat link } \\
\text { lupa } \\
\text { password. } \\
\text { Link sign in } \\
\text { dan create an } \\
\text { account } \\
\text { yang } \\
\text { digunakan } \\
\text { untuk akun } \\
\text { baru. Jika }\end{array}$ & $\begin{array}{c}\text { Sistem } \\
\text { menampilka } \\
\text { n halaman } \\
\text { login. Disaat } \\
\text { user } \\
\text { memasukkan } \\
\text { username } \\
\text { dan atau } \\
\text { password } \\
\text { salah, sistem } \\
\text { menampilka } \\
\text { n pesan } \\
\text { "Username } \\
\text { tidak } \\
\text { terdaftar" / } \\
\text { "Password } \\
\text { salah". Jika } \\
\text { valid maka } \\
\text { sistem akan } \\
\text { membuka }\end{array}$ & $\begin{array}{c}\text { [x] Diterima } \\
\text { [ ] Ditolak }\end{array}$ \\
\hline
\end{tabular}




\begin{tabular}{|c|c|c|c|}
\hline $\begin{array}{l}\text { Aktivitas } \\
\text { Pengujian }\end{array}$ & $\begin{array}{l}\text { Realisasi } \\
\text { yang } \\
\text { diharapkan }\end{array}$ & $\begin{array}{c}\text { Hasil } \\
\text { Pengujian }\end{array}$ & Kesimpulan \\
\hline & $\begin{array}{l}\text { username } \\
\text { dan } \\
\text { password } \\
\text { benar akan } \\
\text { masuk ke } \\
\text { halaman } \\
\text { utama. Jika } \\
\text { tidak akan } \\
\text { menampilka } \\
\text { n pesan } \\
\text { kesalahan } \\
\text { username } \\
\text { dan } \\
\text { password }\end{array}$ & $\begin{array}{c}\text { halaman } \\
\text { utama }\end{array}$ & \\
\hline $\begin{array}{c}\text { Ask } \\
\text { Dokter }\end{array}$ & $\begin{array}{c}\text { Sistem akan } \\
\text { menampilka } \\
\text { n halaman } \\
\text { ask dokter } \\
\text { yang } \\
\text { berfungsi } \\
\text { layaknya } \\
\text { chat tanya } \\
\text { jawab antara } \\
\text { pasien dan } \\
\text { dokter yang } \\
\text { dipilih, atau } \\
\text { yang sedang } \\
\text { online }\end{array}$ & $\begin{array}{c}\text { Sistem } \\
\text { berjalan } \\
\text { baik, staf } \\
\text { marketing } \\
\text { yang } \\
\text { mencoba } \\
\text { berperan } \\
\text { menjadi } \\
\text { pasien } \\
\text { melakukan } \\
\text { chating ask } \\
\text { dokter yang } \\
\text { dijawab oleh } \\
\text { staf client } \\
\text { service yang } \\
\text { berperan } \\
\text { menjadi } \\
\text { dokter. }\end{array}$ & $\begin{array}{c}\text { [x] Diterima } \\
\text { [ ] Ditolak }\end{array}$ \\
\hline $\begin{array}{l}\text { Pilih } \\
\text { jadwal } \\
\text { dokter }\end{array}$ & $\begin{array}{l}\text { Sistem akan } \\
\text { menampilka } \\
\mathrm{n} \text { halaman } \\
\text { appointment. } \\
\text { Pasien dapat } \\
\text { membuat } \\
\text { perjanjian } \\
\text { dengan } \\
\text { dokter } \\
\text { dengan } \\
\text { melihat } \\
\text { jadwal } \\
\text { dokter serta } \\
\text { history } \\
\text { appointment. }\end{array}$ & $\begin{array}{l}\text { Sistem } \\
\text { menampilka } \\
\text { n halaman } \\
\text { appointment. } \\
\text { Selanjutnya } \\
\text { mencoba } \\
\text { untuk } \\
\text { membuat } \\
\text { perjanjian } \\
\text { dengan } \\
\text { dokter } \\
\text { terlebih } \\
\text { dahulu } \\
\text { melihat } \\
\text { jadwal } \\
\text { dokter } \\
\text { praktek. } \\
\text { User dapat } \\
\text { melihat juga } \\
\text { history } \\
\text { perjanjian }\end{array}$ & $\begin{array}{l}\text { [x] Diterima } \\
\text { [ ] Ditolak }\end{array}$ \\
\hline
\end{tabular}




\begin{tabular}{|c|c|c|c|}
\hline $\begin{array}{l}\text { Aktivitas } \\
\text { Pengujian }\end{array}$ & $\begin{array}{c}\text { Realisasi } \\
\text { yang } \\
\text { diharapkan }\end{array}$ & $\begin{array}{c}\text { Hasil } \\
\text { Pengujian }\end{array}$ & Kesimpulan \\
\hline & & $\begin{array}{l}\text { yang telah } \\
\text { dibuat } \\
\text { sebelumnya. }\end{array}$ & \\
\hline $\begin{array}{l}\text { Cetak } \\
\text { laporan } \\
\text { complaint } \\
\text { berdasarka } \\
\text { n kategori }\end{array}$ & $\begin{array}{l}\text { Sistem } \\
\text { menampilka } \\
\mathrm{n} \text { grafik } \\
\text { complaint } \\
\text { per kategori } \\
\text { dengan } \\
\text { memilih } \\
\text { periode } \\
\text { tahun. User } \\
\text { dapat juga } \\
\text { mendownloa } \\
\text { d hasil } \\
\text { laporan } \\
\text { kedalam file } \\
\text { pdf. }\end{array}$ & $\begin{array}{l}\text { Secara } \\
\text { default } \\
\text { sistem } \\
\text { menampilka } \\
\text { n grafik } \\
\text { complaint } \\
\text { per kategori } \\
\text { dengan } \\
\text { tahun } \\
\text { berjalan. } \\
\text { User dapat } \\
\text { memilih } \\
\text { tahun dan } \\
\text { sistem akan } \\
\text { menampilka } \\
\text { n grafik } \\
\text { sesuai } \\
\text { inputan. File } \\
\text { pdf } \\
\text { berdasarkan } \\
\text { hasil } \\
\text { download } \\
\text { sama dengan } \\
\text { apa yang } \\
\text { dilihat di } \\
\text { layar. }\end{array}$ & $\begin{array}{l}\text { [x] Diterima } \\
\text { [ ] Ditolak }\end{array}$ \\
\hline
\end{tabular}

\section{KESIMPULAN}

Berdasarkan hasil dan pembahasan penelitian yang telah lakukan di RSIA XYZ, ditarik kesimpulan, yaitu :

a. Pada masalah tidak adanya wadah untuk menyampaikan testimony, peneliti membuat fitur testimony pada website rumah sakit. Hal ini bertujuan agar pasien lama dapat menyampaikan testimony-nya sehingga calon pasien merasa yakin untuk melakukan treatment di rumah sakit ini.

b. Pada masalah pasien yang kecewa terhadap pelayanan rumah sakit dan menyampaikan keluhan via media sosial, peneliti mengambil kesimpulan untuk membuat fitur complaint pada website rumah sakit. Hal ini bertujuan agar pasien dapat menyampaikan keluhan secara terstruktur dengan memilih kategori complaint sesuai dengan keluhannya.

c. Pada masalah pasien yang kecewa terhadap proses bisnis rumah sakit yang terlampau panjang, peneliti mengambil kesimpulan untuk membuat fitur AskDoctor. Fitur ini dapat memudahkan pasien untuk melakukan konsultasi online terhadap dokter sehingga pasien tidak perlu merasa kesulitan untuk mengikuti prosedur konsultasi offline di rumah sakit.

d. Pada masalah belum adanya fitur appointment untuk konsultasi offline, peneliti mengambil kesimpulan untuk membuat fitur appointment. Fitur ini memberi kemudahan bagi pasien untuk membuat appointment terhadap dokter sehingga pasien tidak perlu menunggu terlalu lama di 
rumah sakit untuk melakukan booking dokter. Serta membuat fitur reminder appointment by whatsapp agar pasien tidak lupa dengan jadwal check-up.

e. Pengujian aplikasi dengan menggunakan black box testing dapat diterima 100\% dari 29 fitur yang diujikan setelah dilakukan dua kali pengujian.

f. Saran untuk penelitian selanjutnya yaitu dengan menambahkan fitur pada fungsi marketing untuk membantu bagian marketing RSIA berupa "manajemen lead" untuk pengelolaan suspect dan prospect pasien agar selanjutnya dapat melakukan transaksi pertama kali di RSIA. Selain itu saran ke depannya dapat dikembangkan aplikasi berbasis mobile agar lebih intuitif dan responsif.

\section{DAFTAR PUSTAKA}

[1] A. Kurniawan, "Hubungan Mutu Kesehatan dengan Kepuasan Pasien Rawat Jalan di Rumah Sakit Tingkat IV Slamet Riyadi Surakarta," INFOKES, vol. VIII, pp. 43-50, 2017.

[2] R. Vidila, "Pemodelan Electronic Customer Relationship Management (E-Crm) Pada Rumah Sakit," Prosisko, vol. V, pp. 87-91, 2018.

[3] F. Rahayu. and H. Irawan, "Perancangan Sistem Electronic Customer Relationship Management (E-Crm) Guna Membantu Meningkatkan Pelayanan Dan Loyalitas Pelanggan Studi Kasus: Lembaga Pendidikan Kumon", IDEALIS : InDonEsiA journaL Information System, 2(4), pp. 205-212, 2018.

[4] I. Tiyani And H. Irawan, "Rancang Bangun Sistem Informasi Electronic Customer Relationship Management (e-Crm) Guna Meningkatkan Pelayanan Serta Loyalitas Pelanggan Studi Kasus : PT Djaya Bersama Putra Prima”, IDEALIS : InDonEsiA journaL Information System, 2(4), pp. 118-124, 2018.

[5] A. Sulkanawatul, H. Pradibta, and I. D. Wijaya, "Aplikasi Customer Relationship Management (CRM) Pada Balai Kesehatan Masyarakat (BKM) Muslimat Kepanjen,” Jurnal Informatika Polinema, vol. 3, no. 2, 2017.

[6] Sutariyani, K. Hamidjoyo, S. Adelya "Electronic Customer Relationship Management (ECRM) pada RSU Assalam Gemolong," Indonesian Journal on Networking and Security, vol. 6, no. 2, 2017.

[7] T. Nurhadiyan. V. Rosalina, "Pemodelan Electronic Customer Relationship Management (ECRM) pada Rumah Sakit,” Jurnal PROSISKO, vol. 5, no. 2, 2018.

[8] D. Fitaloka, "Perbandingan Algoritma Greedy dan Hill Climbing," Jurnal Teknik Informatika Kaputama, vol. 11, no. 2, pp. 13-24, 2017.

[9] Muslihudin and Oktafianto, "Analisis dan Perancangan Sistem Informasi Menggunakan Model Terstruktur dan UML”, Yogyakarta: CV. Andi Offset, 2016.

[10] S. Mulyani, "Metode Analisis dan Perancangan Sistem", 2nd ed., Bandung: Abdi Sistematika,2016 